Copyright (C) 2014 IEEE. Personal use of this material is permitted. Permission from IEEE must be obtained for all other uses, in any current or future media, including reprinting/republishing this material for advertising or promotional purposes, creating new collective works, for resale or redistribution to servers or lists, or reuse of any copyrighted component of this work in other works. 


\section{Modeling the Relationships between}

\section{Perceptions about Technology and Attitudes toward Computers}

\author{
Myint Swe Khine \\ Assessment and Evaluation Centre \\ Emirates College for Advanced Education \\ Abu Dhabi, United Arab Emirates \\ E-mail: mskhine@ecae.ac.ae
}

\author{
Ernest Afari \\ Petroleum Institute \\ Abu Dhabi, United Arab Emirates \\ E-mail: ernest.afari@gmail.com
}

\begin{abstract}
Over the past few years, the relationship between attitudes and behavior has been of a major interest to educators. Previous studies have found varying degree of associations between attitudes, behavioral intention and perceptions and corroborate the fact that attitudes influence patterns of behavior. As computer technology is becoming pervasive in the society, researchers have attempted to explore the links between individual's perceived ease of use, perceived usefulness and their intention to use the computer technology. A study was conducted in two higher education institution in the United Arab Emirates to find out students' intention to use computer technology employing the Technology Acceptance Model (TAM) by Reference [1] as a theoretical framework and Structural Equation Modeling as an analytical tool. The results revealed strong relationships between the students' attitudes toward computer and intention to use. This paper further reports the applicability of technology acceptance model and its robustness and generalizability in different research contexts.
\end{abstract}

Keywords - technology acceptance, behavioral intention, attitudes, computers

\section{INTRODUCTION}

The research into how students' attitudes affect their learning of specific subjects has been a core area of interest among educators in schools and higher learning institutions. The development of attitudes research records various attempts at measuring attitudes and determining the correlations between behaviour, achievements, career aspirations, gender identity, and cultural differences [2]. The important role of attitude and its effect on curriculum design and instructional strategies is also well documented.

\section{TECHCHOLOGY ACCEPATNCE}

In exploring the factors that are concerned with the use of computer technology and related devices, research in behavioural and social science offers the theoretical frameworks for understanding the technology acceptance. Reference [3] developed a theory of reasoned action (TRA), which suggests that behaviour is well predicted from the behavioural intentions. In the same vain the behavioural intentions were predictable by attitudes toward the possible behaviour. To extend the TRA model, Reference [4] proposed the theory of planned behaviour (TPB), which included an additional variable named perceived behaviour control. The perceived behaviour control refers to people's perceptions of their ability to perform a given behaviour. Figure I depicts the Theory of Planned behaviour proposed by Reference [4].

One of the most influential extensions of the theory of reasoned action (TRA) developed by Reference [3] was the technology acceptance model (TAM) by Reference [1] TAM assumes that the behavioural intention to use a particular technology is an important factor that can lead to the actual usage of such technology. A number of studies that used TAM as a framework were able to explain user behaviours in computers and related technologies. For example, the study [5] used technology acceptance model approach to explore the influence of work and social/leisure contexts and also course study on attitudes towards technology. Their results indicated that usefulness and ease of use are key aspects of students' attitudes towards technology. In another study [6] the researchers used technology acceptance model to explain students' acceptance of collaborative technologies. 136 students participated in their study, using Google Applications to support the project work that students are engaging. The study suggested that the subjective norm represented by peers significantly moderates the relationship between attitude and intention toward the technology.

In a study conducted within the context of blended learning, a group of researchers [7] examined the determinant of technology acceptance and use, such as perceived usefulness and gender difference. The results suggested that there exists gender difference in the effect of perceived usefulness in student attitude towards a technology and intention to use such technology. Another study by Reference [8] described perceived affective quality, in particular affective reactions towards technology as an important dimension in user technology acceptance. 


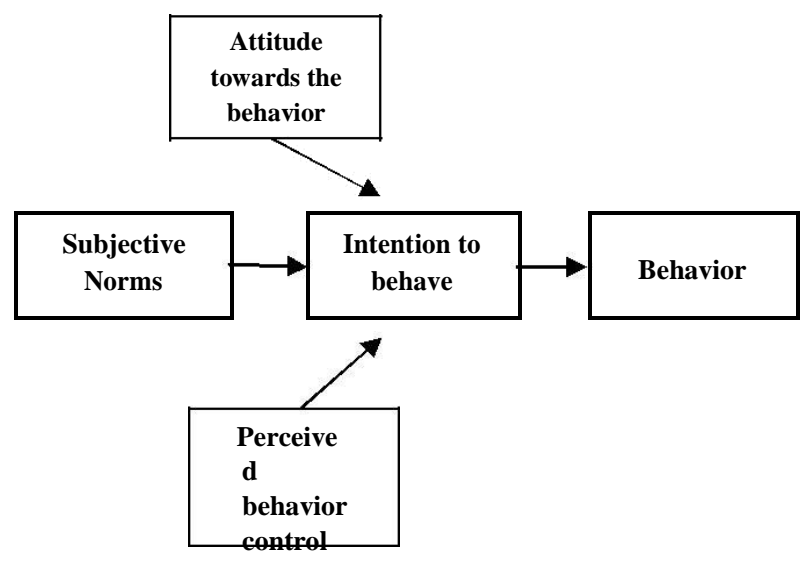

Figure 1: The Theory of Planed Behaviour [4]

In a study conducted within the context of blended learning, a group of researchers [7] examined the determinant of technology acceptance and use, such as perceived usefulness and gender difference. The results suggested that there exists gender difference in the effect of perceived usefulness in student attitude towards a technology and intention to use such technology. Another study by Reference [8] described perceived affective quality, in particular affective reactions towards technology as an important dimension in user technology acceptance.

In recent years, a number of meta-analyses have been conducted to examine the technology acceptance model. One such attempt [9] based on 26 selected empirical studies to synthesize the empirical evidence to determine the significant relationships between usefulness, acceptance and ease of use. The results indicated a strong relationship between perceived ease of use (PEU) and perceived usefulness (PU) and technology acceptance (TA), confirming Reference [1] original findings. It was also found that the relationship between PEU and TA was weak. Similar study [10] we also conducted involving 88 published papers. The study found that Perceived Usefulness (PU) and Behavioural Intention (BI) were highly reliable to use in various contexts. It was also found that the influence of perceived usefulness on behavioural intention was high. The authors noted that often participants of the studies were students who were used as convenient samples and study that involves actual users in work environments may be necessary to test the effects. However, the authors concluded that technology acceptance can be assessed using TAM as a valid and robust model.

\section{THE STUDY}

The purpose of this study was to investigate the applicability of the Technology Acceptance Model when used with a group of tertiary students in the United Arab Emirates. The UAE is an affluent society and most students own multiple devices and active in the use of laptops, tablets and mobile phones. In the study conducted by Reference [11] with female students in the UAE, it was found that students, not only used mobile devices for social occasions, but they also used for informal learning activities outside of the classrooms. Students used SMS and phone calls because they perceived them as useful for their learning.

The aim of this study had twofold. The first aim was to explore whether the Technology Acceptance Model was applicable to use in this context to explain students' intention to use computer technology, and the second aim was to discover the significant relationships in the TAM framework.

As a first step, confirmatory factor analysis was employed to validate the questionnaire used in the study. We used structural equation modeling (SEM) to assess the research model, based on both theory and research in the second step. The research model is represented in Figure II.

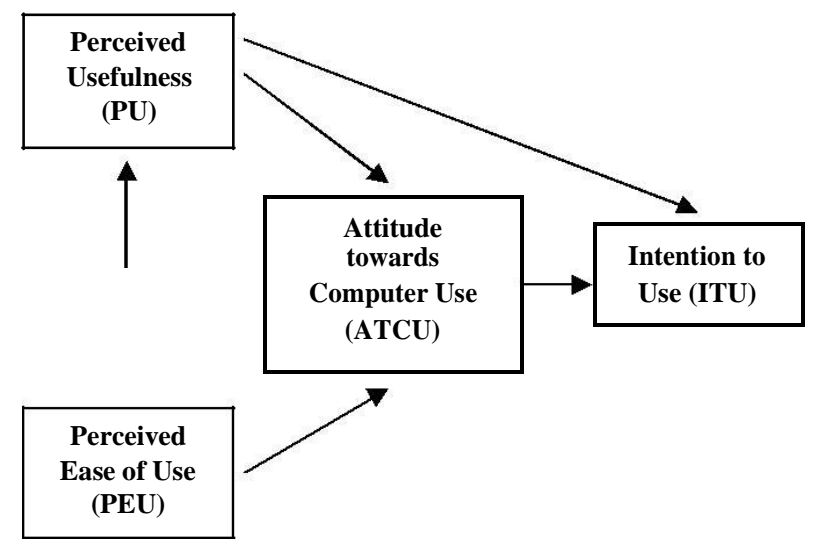

FIGURE II. THE RESEARCH MODEL OF THE STUDY

* Adapted from [1]

The following five hypotheses were generated based on the research questions:

H1: PEU will have a significant influence on PU.

H2: PEU will have a significant influence on ATCU.

H3: PU will have a significant influence on ATCU.

H4: ATCU will have a significant influence on ITU.

H5: PU will have a significant influence on ITU.

According to Reference [12] SEM is a statistical approach to testing hypothesis about the relationships among observed and latent variables. Previous studies have indicated that SEM is suitable for validating and testing models. Besides, SEM models measurement errors and provides more accurate measurements at the item and construct levels [13].

Participants were 327 students from two tertiary institutions in the United Arab Emirates (UAE). Their mean age was 19.77 years $(\mathrm{SD}=1.73)$ and $57.2 \%$ (187) were males and $42.8 \%$ (140) were females. All of the students owned laptop computers and tablets and the number of years in using these devices are 3.65 years $(\mathrm{SD}=1.40)$ for the laptop computers and 1.66 years $(\mathrm{SD}=1.06)$ for the tablets. 
A self-report questionnaire was used in this study. The questionnaire comprised two parts; the first part solicited the background information of the students such as gender and age. Students' experience in using mobile devices and average amount of time they spent on mobile devices were also included in this part. The second part of the questionnaire covered 12 items statements on four constructs adapted from Reference [14]. The constructs used in this study were perceived ease of use (PEU), perceived usefulness (PU), attitude towards computer use (ATCU) and intention to use (ITU). Each of these constructs had three items. Details of the constructs and operational definitions are shown in Table I. The students provided their perceptions on five-point Likert scale with $5=$ strongly agree to $1=$ strongly disagree. The English language competencies of the students were acceptable and as such the questionnaire was administered in English language.

\section{TABLE I. CONSTRUCTS AND OPERATIONAL DEFINITIONS}

\begin{tabular}{|l|l|}
\hline \multicolumn{1}{|c|}{ Construct } & \multicolumn{1}{c|}{ Operational definitions } \\
\hline $\begin{array}{l}\text { Perceived } \\
\text { Usefulness }\end{array}$ & $\begin{array}{l}\text { Using computer will improve my } \\
\text { work }\end{array}$ \\
\hline $\begin{array}{l}\text { Perceived Ease of } \\
\text { Use }\end{array}$ & $\begin{array}{l}\text { My interaction with computers is } \\
\text { clear and understandable }\end{array}$ \\
\hline $\begin{array}{l}\text { Attitudes toward } \\
\text { Computer Use }\end{array}$ & $\begin{array}{l}\text { Computers make work more } \\
\text { interesting }\end{array}$ \\
\hline Intention to Use & I will use computer in future \\
\hline
\end{tabular}

\section{FINDINGS}

The descriptive statistics of the constructs (Perceived usefulness, perceived ease of use, attitude towards computer use, and intention to use), are shown in Table II. All mean scores were greater than 3.0, ranging from 4.15 to 4.31 . This indicated an overall positive response to the constructs measured in this study. The standard deviations for all the constructs were less than one, ranging from .76 to .84 , indicating that the item scores were narrowly spread around the mean. The skewness index ranged from -.25 to -.41 and kurtosis index ranged from .06 to .34 . As recommended by [15], the skewness and kurtosis indices should be below an absolute value of 3.0 and 8.0, respectively. We therefore concluded that the data in our study had no severe problems and were considered normal for the purpose of structural equation modeling.

\section{TABLE II. DESCRIPTIVE STATISTICS AND CORRELATIONS OF CONSTRUCTS}

\begin{tabular}{|l|l|c|l|c|l|l|l|l|}
\hline Con & Mean & SD & Skew & Kur & PU & PEU & ACT & ITU \\
\hline PU & 4.24 & .80 & -.33 & .06 & $\mathbf{. 8 2}$ & & & \\
\hline PEU & 4.22 & .76 & -.25 & .14 & $.67 * *$ &. $\mathbf{7 5}$ & & \\
\hline ATCU & 4.15 & .84 & -.34 & .25 & $.59^{* *}$ & $.72^{* *}$ & $\mathbf{. 7 6}$ & \\
\hline ITU & 4.31 & .82 & -.41 & .34 & $.57^{* *}$ & $.64^{* *}$ & $.64^{* *}$ & $\mathbf{. 7 9}$ \\
\hline
\end{tabular}

Note: $* * p<.01$
Diagonal elements (bold) are the square root of average variance extracted (AVE) between the constructs and their measures. Off-diagonal elements are correlations between constructs.

\section{A. Reliability and Validity}

As proposed by Reference [16] we examined item reliability of each measure and composite reliability of each construct. At the item level, the minimum requirement suggested for factor loadings is .70 [17][18][19][20]. At the construct level, an alpha of .70 and higher was recommended to reflect adequate reliability [21].

Table III shows that the reliabilities of all the constructs ranged from .80 to .86 , which were above the minimum value recommended by Reference [21].

TABLE III. COMPOSITE RELIABILITY OF THE CONSTRUCTS

\begin{tabular}{|c|c|}
\hline Construct & $\begin{array}{c}\text { Composite } \\
\text { Reliability (CR) }\end{array}$ \\
\hline Perceived Usefulness & .86 \\
\hline Perceived Ease of Use & .80 \\
\hline Attitude Towards Computer Use & .80 \\
\hline Intention to Use & .83 \\
\hline
\end{tabular}

\section{B. Test of the Measurement Model}

Structural equation approach was used to test the research model in this study. As recommended by References [22] and [15], a variety of fit indices were used to measure model fit in our study. These were: the chi-square $(\chi 2)$, the ratio of $\chi^{2}$ to its degree of freedom $(\chi 2 / \mathrm{df})$, Tucker- Lewis index (TLI), the comparative fit index (CFI), the root mean square error of approximation (RMSEA), and the standardized root mean square residual (SRMR). The result of the model fit as shown by the various fit indices in Table IV indicated that the research model fits the data fairly well.

TABLE IV. FIT INDICES OF THE PROPOSED RESEARCH MODEL

\begin{tabular}{|c|c|c|}
\hline Fit index & Values & $\begin{array}{c}\text { Level of } \\
\text { acceptable fit }\end{array}$ \\
\hline$\chi^{2}$ & $139.6, P<.05$ & Non-significant \\
\hline$\chi^{L} /$ df & 2.847 & $<3$ \\
\hline TLI & 0.945 & $\geq .90$ \\
\hline CFI & 0.959 & $\geq .90$ \\
\hline RMSEA & 0.075 & $<0.5$ \\
\hline SRMR & 0.042 & $<.05$ \\
\hline
\end{tabular}

TLI, Tucker-Lewis index; CFI, Comparative fit index; RMSEA, root mean square error of approximation; SRMR, Standardized root mean square residual

The overall results (see Table V) indicated that four out of five hypotheses were supported by the data. Perceived

Proceedings of the International Conference on Education Technologies and Computers, Lodz University of Technology, Lodz, Poland, September 22-24, 2014. ISBN: 978-1-4799-6247-1 
usefulness (PU) did not have a significant influence on Attitude towards computer use (ATCU) $(\beta=-.09, \mathrm{p}>.05)$, therefore, it did not support $\mathrm{H} 3$ but had a significant influence on intention to use (ITU) $(\beta=.326, p<.001)$, supporting H5. Perceived ease of use (PEU) had a significant influence on perceived usefulness (PU) $(\beta=.80, p<.001)$ and attitude towards computer use (ATCU) $(\beta=.97, p<.001)$, supporting H1 and H2. Finally, attitude towards computer use (ATCU) had a significant influence on intention to use (ITU) $(\beta=.554, \mathrm{p}<$

.001), supporting H4.

We tested three endogenous variables (PU, ATCU, ITU) in the research model. Perceived usefulness was found to be predicted by perceived ease of use, resulting in an R2 of .635. This means that perceived ease of use explained $63.5 \%$ of the variance in perceived usefulness. Also, attitude towards computer use was found to be predicted by perceived ease of use and perceived usefulness, resulting in an R2 of .813. This means that perceived ease of use and perceived usefulness explained $81.3 \%$ of the variance in attitude towards computer use. Finally, intention to use was found to be predicted by attitude towards computer use and perceived usefulness, resulting in an $\mathrm{R} 2$ of .66. This means that attitude towards computer use and perceived usefulness explained $66 \%$ of the variance in intention to use. The results of the hypotheses testing and path coefficients of the proposed model are reported in Table 5.

\section{TABLE V. RESULTS OF HYPOTHESIS TESTS}

\begin{tabular}{|c|c|c|c|}
\hline Hypothesis & Path & $\begin{array}{c}\text { Path } \\
\text { coefficient }\end{array}$ & $t$-value \\
\hline $\mathrm{H} 1$ & PEU $\rightarrow$ PU & $0.797 * * *$ & 10.875 \\
\hline $\mathrm{H} 2$ & PEU $\rightarrow$ ATCU & $0.971 * * *$ & 7.244 \\
\hline H3 & PU $\rightarrow$ ATCU & -0.089 & -0.826 \\
\hline H4 & ATCU $\rightarrow$ ITU & $0.554 * * *$ & 6.812 \\
\hline H5 & PU $\rightarrow$ ITU & $0.326^{* * *}$ & 4.426 \\
\hline
\end{tabular}

PU, perceived usefulness; PEU, perceived ease of use; ATCU, attitude towards computer use; ITU, intention to use. $* * * p<0.001$

\section{DISCUSSION}

The study explored (i) the applicability of technology acceptance model on a sample of tertiary students in the UAE and (ii) the significant relationships between perceived usefulness, perceived ease of use, and attitude towards computer use and intention to use. Five hypotheses were tested in this study. It was found that perceived ease of use had direct effect on perceived usefulness and in turn affected the intention to use. Attitude towards computer use also affected the intention to use. Four out of five hypotheses were found to be supported in the model. With the exception of H3, all the hypotheses were significant. There was no significant relationship between perceived usefulness and the attitude towards computer use. This suggests that, although most students in the UAE use computers for their daily activities (messaging, chatting, emailing, games, etc), they are not well exposed to computers in the classroom. Therefore, this research should encourage educators in the UAE to incorporate the use of computers in the classroom to enhance student learning. These findings are similar to the study reported by Reference [23] with the sample in the UK.

It should also be noted that the questionnaire used in this study was in English and not translated into Arabic. There may be some issues in interpreting the meaning of the question items when the students respond the questionnaire. In addition the study involved only students in two institutions in the UAE, hence limiting the power of statistical analyses. Wider sampling that involves students from other higher learning institutions might have made the sample more representative. Issues related to the use of self-report questionnaire in empirical research have been raised in the past [24]. It is assumed that data collected from self-report questionnaire is the truthful reflection of their actual action. In order to gain better understanding of the intention to use technology and TAM, longitudinal studies may be necessary.

\section{CONCLUSION}

As indicated in the literature review, TAM framework has been used to explain the technology acceptance in various contexts. The results from this study suggest that the TAM is a viable and consistent model to explain the intention of the use of technology among tertiary students in the United Arab Emirates. This study also contributes to the literature on technology acceptance of students from the UAE perspective. This is a pioneering attempt and findings from this study contribute to the existing literature. The study also meets the recommendations of other studies on the need to validate the TAM in different contexts, culture and perspective.

\section{REFERENCES}

[1] F.D. Davis. "Perceived usefulness, perceived ease of use, and user acceptance of information technology". MIS Quarterly, pp. 319-340 (1989).

[2] M.S. Khine, \& I. Saleh. "Attitude research in science education: Looking back, looking forward". In M.S. Khine \& I. Saleh (Eds.). Attitude research in science education: Classic and contemporary measurements. Charlotte, North Carolina: Information Age Publications, 291-296 (2011).

[3] I, Ajzen, \& M, Fishbein, M. "Attitude behavior relations: A theoretical analysis and review of empirical research". Psychological bulletin, Vol. 84, No. 5, pp 888-918 (1977).

[4] I, Ajzen, I. "Attitude personality and behaviour". Chicago: Dorsey (1989).

[5] R, Edmunds, M. Thorp, \& G. Conole, "Student attitudes towards and use of ICT in course study, work and social activity: A technology acceptance model approach". British journal of educational technology, Vol. 43, No.1, pp. 71-84 (2012).

[6] R, Cheung, \& D. Vogel. "Predicting user acceptance of collaborative technologies: An extension of the technology acceptance model for elearning". Computers \& Education, Vol. 63, pp. 160-175 (2013).

[7] A. Padilla-Meléndez, A. R. del Aguila-Obra, \& A. Garrido-Moreno. "Perceived playfulness, gender differences and technology acceptance model in a blended learning scenario". Computers \& Education, Vol. 63, pp. 306-317 (2013).

Proceedings of the International Conference on Education Technologies and Computers, Lodz University of Technology, Lodz,

Poland, September 22-24, 2014. ISBN: 978-1-4799-6247-1 
[8] M.J. Sanchez-Franco. "WebCT-The quasimoderating effect of perceived affective quality on an extending Technology Acceptance Model". Computers \& Education, Vol. 54, No.1, pp. 37-46 (2010).

[9] Q. Ma, \& L. Liu. "The technology acceptance model: a meta-analysis of empirical findings". Journal of Organizational and End User Computing (JOEUC), Vol.16, No. 1. pp. 59-72 (2004).

[10] W.R. King, \& J. He. "A meta-analysis of the technology acceptance model". Information \& Management, Vol. 43, No. 6, pp. 740-755 (2006).

[11] I. Santos, \& N. Ali. "Exploring the uses of mobile phones to support informal learning" . Educational Information Technology, Vol. 17, pp. 187-203 (2012).

[12] M.S. Khine. "Application of structural equation modeling in educational research and practice". Rotterdam, the Netherlands: Sense Publishers (2013).

[13] T. Teo, T., \& M.S. Khine, M.S. "Structural equation modeling in educational research: Concepts and applications". Rotterdam, the Netherlands: Sense Publishers (2009).

[14] T. Teo. "Evaluating the intention to use technology among student teachers: A structural equation modeling approach". International Journal of Technology in Teaching Learning, Vol. 5, No.2, pp. 106-118 (2009).

[15] R.B. Kline. "Principles and practices of structural equation modeling (3rded.)". New York: Guilford Press (2010).
[16] C. Fornell, \& D.F. Larker, "Evaluating structural equation models with unobservable variables and measurement error". Journal of Marketing Research, Vol.18, pp. 39-50 (1981).

[17] D. Barclay, C. Higgins, \& R. Thompson. "The Partial Least Squares (PLS) approach to causal modeling: Personal computer adoption and uses as an illustration". Technology Studies, Vol.2, pp. 285-309 (1995).

[18] J.F. Hair, W.C. Black, B.J. Babin, \& R.E. Anderson. "Multivariate data analysis, (7thed.)". Upper Saddle River, New Jersey: Prentice-Hall (2010).

[19] W.W. Chin, W.W. "Issues and opinion on structural equation modeling". MIS Quarterly, pp. vii- xvi (1998).

[20] J. Hulland. (1999). "Use of partial least squares (PLS) in strategic management research: A review of four recent studies". Strategic Management Journal, Vol .20, pp.195-204 (1999).

[21] J.C. Nunnally, \& I. H. Bernstein. "Psychometric theory", New York, NY: McGraw-Hill, Inc (1994).

[22] D. Harrington. "Confirmatory Factor Analysis". New York, NY: Oxford University Press (2009).

[23] T. Teo, \& J. Noyes. "Exploring attitudes towards computer use among pre-service teachers from Singapore and the UK: A multi-group invariance test of the technology acceptance model (TAM)". Multicultural Education \& Technology Journal, Vol. 4, No. 2, pp. 126135 (2010).

[24] N. Schwarz. "Self-reports: how the questions shape the answers. American psychologist, Vol. 54, No. 2, pp. 93-105 (1999).

Proceedings of the International Conference on Education Technologies and Computers, Lodz University of Technology, Lodz, Poland, September 22-24, 2014. ISBN: 978-1-4799-6247-1 